\title{
Kurtbağrı (Ligustrum lucidum) odununun bazı mekanik özelliklerinin araştırılması ve diğer bazı ağaç türleri ile karşılaştırılması
}

\author{
Vedat Çavuş*(i)
}

\section{$\ddot{\mathbf{O} z}$}

Ağaç malzemenin kullanılacağı yere karar verilebilmesi ve kullanım amacına en uygun olarak seçilebilmesi için fiziksel, mekanik, kimyasal ve teknolojik özelliklerinin bilinmesi gereklidir. $\mathrm{Bu}$ özelliklerin bilinmesi; tasarımcılar, üreticiler, tüketiciler, mühendisler, mimarlar için oldukça önemlidir. Bu çalışmada, kurtbağrı (Ligustrum lucidum) odununun bazı önemli fiziksel ve mekanik özellikleri araştırılmıştır. Hava kurusu yoğunluk, eğilme direnci, elastikiyet modülü, statik sertlik değeri ve vida tutma kapasitesi belirlenmiştir. Elde edilen verilere göre; hava kurusu yoğunluk $791.53 \mathrm{~kg} / \mathrm{m}^{3}$, eğilme direnci $98,66 \mathrm{~N} / \mathrm{mm}^{2}$, eğilmede elastikiyet modülü $6946.26 \mathrm{~N} / \mathrm{mm}^{2}$, statik sertlik direnci teğet, radyal ve enine yüzeyde sirasıyla $82.58,83.97$ ve $101.82 \mathrm{~N} / \mathrm{mm}^{2}$ olarak tespit edilmiştir. Vida tutma kapasitesi teğet, radyal ve enine yüzeyde sırasıyla $41.04,43.93$ ve $34.77 \mathrm{~N} / \mathrm{mm}^{2}$ olarak tespit edilmiştir. Tespit edilen değerler bazı diğer odun türleri ile karşılaştırılmıştır. Bu odun türünün önemli mekanik özelliklere sahip olduğu sonucuna ulaşılmıştır. Bu odun türü; yüksek derecede sertlik ve eğilme direnci istenen merdiven, döşeme, parke, ayakkabı kalıpları, müzik aletleri, alet yapımı, oyuncak ve ambalaj, her türlü ahşap tornalama ve mobilyalarda kullanılabilir.

Anahtar kelimeler: Kurtbağrı, Ligustrum lucidum, Fiziksel özellikler, Mekanik özellikler

\section{Investigation of some mechanical properties of privet (Ligustrum lucidum) wood and comparison with some other tree species}

\begin{abstract}
It is necessary to determine the physical, mechanical, chemical and technological properties of the wood material in order to decide where it will be used and to be selected in the most appropriate way for its intended use. To know these features; it is very important for designers, manufacturers, consumers, engineers and architects. In this study, some important physical and mechanical properties of Privet (Ligustrum lucidum) wood were investigated. Air-dried density, modulus of rupture, modulus of elasticity, static hardness and screw holding capacity were determined. According to the obtained data; air-dried density; 791.53 $\mathrm{kg} / \mathrm{m}^{3}$, modulus of rupture; $98.66 \mathrm{~N} / \mathrm{mm}^{2}$, modulus of elasticity; $6946.26 \mathrm{~N} / \mathrm{mm}^{2}$, static hardness resistance; $82.58,83.97$ and $101.82 \mathrm{~N} / \mathrm{mm}^{2}$ at tangential, radial and transverse surface, were determined, respectively. Screw holding capacity were determined 41.04, 43.93 and $34.77 \mathrm{~N} / \mathrm{mm}^{2}$ on tangential, radial and transverse surface, respectively. The determined values were compared with some other wood species. It was concluded that this type of wood has important mechanical properties. Privet wood can be used in staircases, flooring, parquet, shoe molds, musical instruments, tool making, toy and packaging, all kinds of wood turning and furniture, where a high degree of hardness and bending resistance is required.
\end{abstract}

Keywords: Privet, Ligustrum lucidum, Physical properties, Mechanical properties

Makale tarihçesi: Geliș: 25.04.2021, Kabul: 09.05.2021, Yayınlanma: 28.06.2021, *e-posta: vedatcavus@ @otmail.com, *İzmir Kâtip Çelebi Üniversitesi, Orman Fakültesi, Orman Endüstri Mühendisliği Bölümü, İzmir/Türkiye Atıf: Çavuş, V., (2021), Kurtbağrı (Ligustrum lucidum) odununda bazı mekanik özelliklerinin araştırılması ve diğer bazı ağaç türleri ile karşılaştırılması, Mobilya ve Ahşap Malzeme Araştırmaları Dergisi, 4(1), 19-29, DOI: 10.33725mamad.927822 


\section{Giriş}

Kurtbağnı (Ligustrum lucidum) ağac1, genellikle Çin kurtbağrı, parlak kurtbağrı veya balmumu yapraklı kurtbağrı, Avrupa kurtbağrı adları ile bilinen ve hızlı yetişen bir ağaç türüdür. Kurtbağrı ağaç türü Dünya çapında dağılım gösteren Oleaceae familyasının bir üyesi olup, Akdeniz havzasının bitki örtüsüne önemli ölçüde katkıda bulunmaktadır (Bailey 1963, Brosse 1979). Kurtbağrı ağacı, güneybatı İsveç ve güneydoğu Norveç'e kadar kuzeye uzanarak Avrupa'nın büyük kısmına özgü bir tür olma özelliği göstermektedir. Aynı zamanda kuzeybatı Afrika'ya (Fas) ve batı Asya'ya (Türkiye, kuzeybatı İran, Ermenistan, Azerbaycan ve Gürcistan) kadar doğuya uzayan bir yayılım gösterir. Ayrıca güneydoğu Avustralya'da Güney Afrika, Yeni Zelanda, ABD ve Güney Kanada'ya kadar yaygın bir şekilde bulunan bu ağaç türü Kuzey ve Güney Amerika (Kanada, ABD, Arjantin ve Brezilya), Güney Afrika, Avustralya ve Yeni Zelanda'da istilacı bir tür olarak rapor edilmiştir (Şofletea ve Curtu 2007, Qin 2009, Enescu ve ark., 2015). Bu ağaç yaprak döken bir ağaç türü olup 4 veya 5 m’ye kadar boy yapabilir. Ülkemizde Karadeniz kıyı şeridinde ve iç bölgelerde doğal olarak yetişir ve kışın fazla sert geçmediği yerlerde yarı her dem yeşildir. Bu ağaç türünün Dünya üzerindeki yayılımı Şekil 1'de gösterilmiştir.

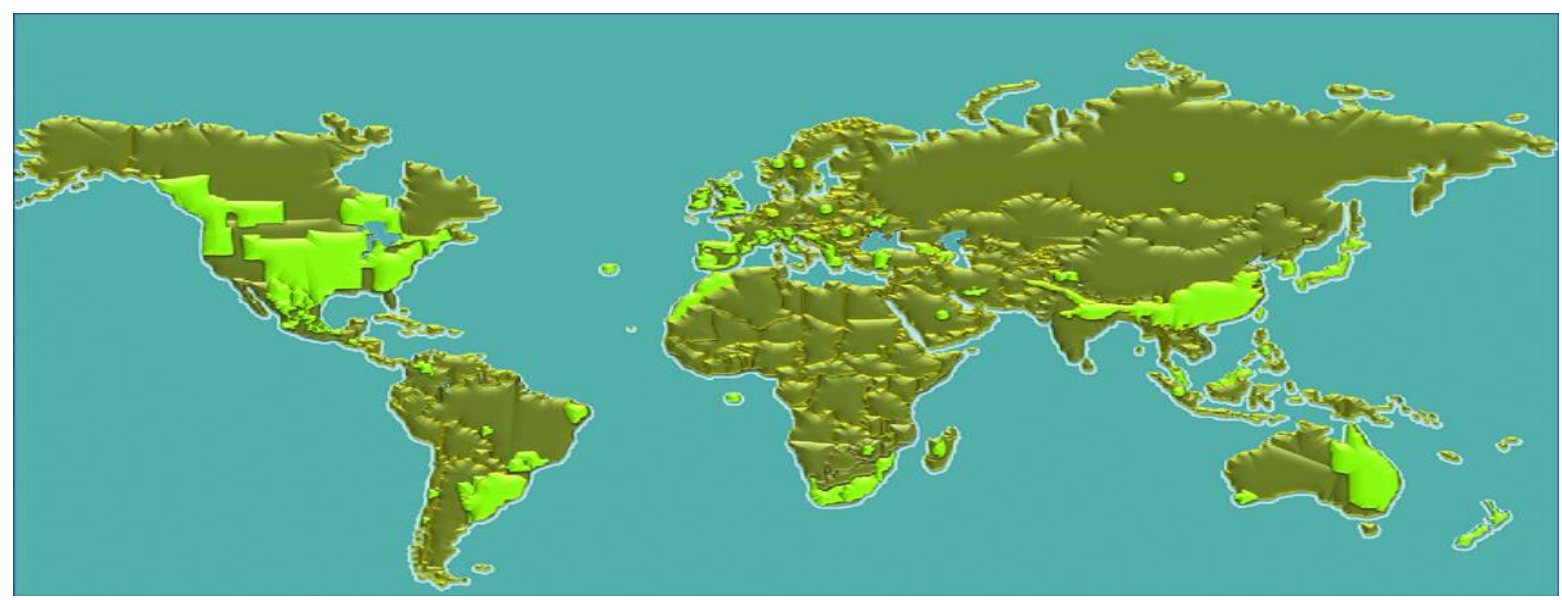

Şekil 1. Dünya üzerinde ve Türkiye'de Ligustrum vulgare ve Ligustrum lucidum ağaç varlığının dağılımı (URL 1).

Genel görünümü, kabuk, yaprak, sürgün, çiçek, meyve ve tohumları Şekil 2'de gösterilen kurtbağrı ağacı, koyu yeşil yapraklı, hızlı büyüyen, gür ve yaprak döken bir çalı şeklinde olduğu bildirilmiştir. Bu ağaç türünün yaprakları yumurta-mızrak şeklinde, $8-12 \mathrm{~cm}$ uzunluğunda, ayanın ucu sivri, tabanı genellikle geniş kama şeklindedir. Yaprak sapı uzunluğu 1-2 cm olup 6-8 çift damar genellikle üst ve alt yüzde belirgindir. Bileşik salkım tipinde kurullar oluşturan çiçekler sapsız gibidir. Meyve oval, yaklaşık $1 \mathrm{~cm}$ uzunlukta, mavi, siyah renklidir. Yaprakları kısa saplı, sürgünlerde karşılıklı olarak dizilmiş, ters-oval ve düz kenarlıdır. Yaprakların ucu sivri ve 3-6 $\mathrm{cm}$ boyundadır. Birçok ülkede peyzaj bitkisi olarak kullanılmaktadır. Beyaz renkteki çiçekler dal uçlarında yer almaktadır. Çiçekler yaz döneminde türlere göre değişmekle beraber haziran-eylül ayları arasında kümeler hâlinde açar ve güzel kokar. (Şofletea ve Curtu 2007, Bagi ve Baseri 2021, URL 2). Şehirlerde yol kenarlarında süs veya çit ağacı olarak kullanılır. 2 veya 2.5 metreye kadar gövdesi dalsız bırakılır. Üstten çok fazla dallanıp budaklanır. İsteğe göre dallanıp budaklanan kısımlarına şekiller verilebilir. Çok hızlı büyüyen bir ağaç türü olduğundan dolayı sürekli budamak gereklidir (Cothran 2003, Pieroni ve Pachaly 2000, Dirr 2009). 
Çölleşme riski altında olan kırılgan alanların korunmasında temel bir rol oynar (Bailey 1963, Brosse 1979, Grubb ve ark., 1996). Gölgeye ve kuraklığa toleranslıdır ve hemen hemen her tür toprakta büyüyebilir (Lieutaghi 1975, Brosse 1979, Bailey 1922, Obeso ve Grubb 1993, Gratani ve Foti 1998, Weber 2003, URL 3).
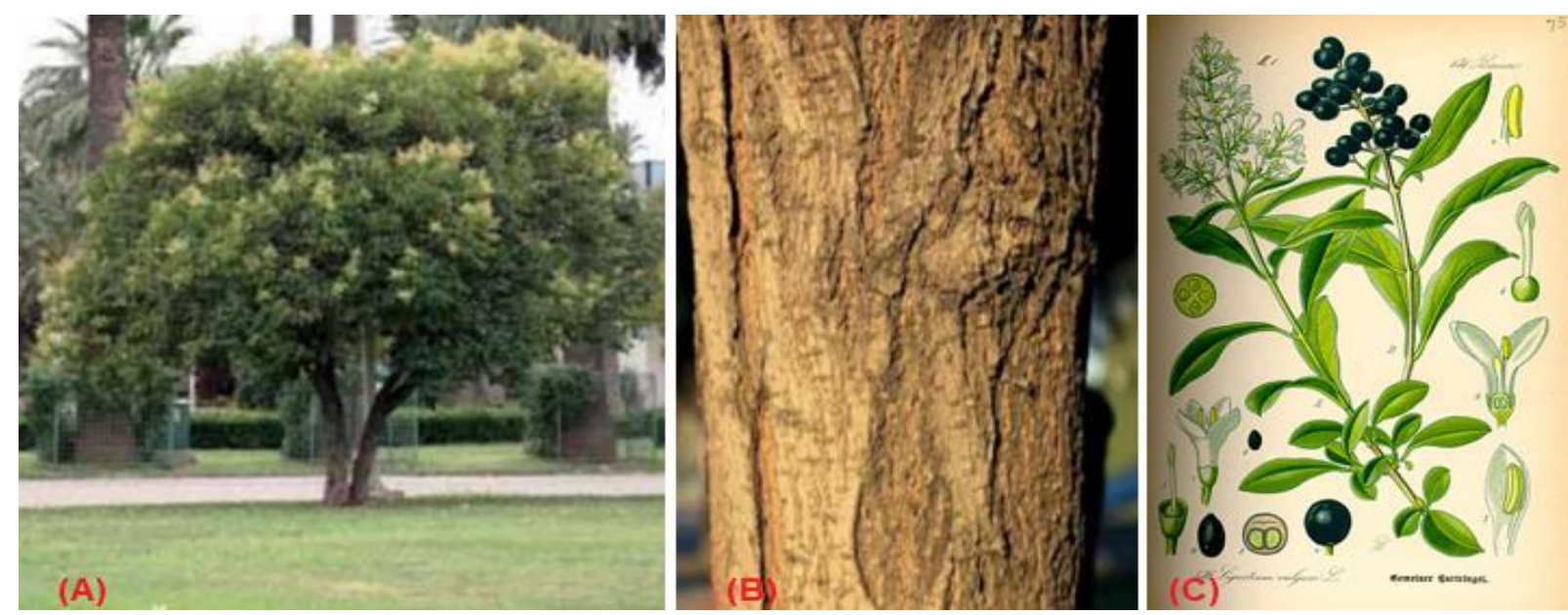

Şekil 2. (A) Kurtbağrı ağacının genel görünümü, (B) Kurtbağrı ağacının gövde ve kabuk görünümü (URL 4), (C) Kurtbağrı ağacının yaprak, sürgün, çiçek, meyve ve tohumlarının görünümü (URL 5).

Kurtbağrı ağacının farklı kısımlarından (yapraklar, meyveler ve çiçekler) elde edilen ekstraktlar geçmişte tıp alanında kanser dahil çeşitli hastalıkların önlenmesi veya tedavisi için kullanılmıştır (Mogosanu ve ark., 2016). Ağaç kabuğundan yapraklardan sarı bir boya elde edilir. Meyvelerden mavimsi-yeşil bir boya elde edilir (Uphof 1959, Usher 1974, Mabey 1979), bu çoğu yeşillikten daha kalıcıdır. Genç dallar sepetçilik ve çit yapımında kullanılır (Uphof 1959, Usher 1974, Polunin 1969). Odunu çoğunlukla odun kömürü üretiminde kullanılmaktadır. Bu ağacın odunu sert, sıkı dokulu olduğundan tornalama işlerinde, baston yapımında ve ayrıca küçük aletler ile tarımsal aletlerin yapımında kullanılmaktadır (Uphof 1959, Usher 1974). Teknik anlamda bir ağaç malzemenin kullanım yerine ve amacına en uygun olarak seçilebilmesi için o malzemenin fiziksel, mekanik, kimyasal ve teknolojik özelliklerinin belirlenmesi, tanıtılması; tasarımcılar, üreticiler, tüketiciler, mühendisler, mimarlar ve akademik çevreler için seçim ve kullanım aşamasında oldukça önemlidir. Yapılan literatür taramasında, kurtbağrı odununun kimyasal, fiziksel ve mekanik özellikleri üzerine yapılmış herhangi bir çalışmaya rastlanmamıştır.

$\mathrm{Bu}$ çalışmada, fiziksel ve mekanik özellikleri üzerinde kapsamlı bir çalışmaya rastlanmayan kurtbağrı (Ligustrum lucidum) odununun bazı mekanik özelliklerinin belirlenmesi amaçlanmıştır. Kurtbağrı odununa ait elde edilen bazı fiziksel ve mekanik özelliklere ait veriler, endüstriyel ve endüstriyel olmayan odun türlerine ait veriler ile karşılaştırılmıştır. Bu çalışmada elde edilen verilerin kurtbağrı odununun kullanım yerine ve aynı zamanda ilgili literatüre katkı sağlayacağı düşünülmektedir.

\section{Materyal ve Metot}

\subsection{Materyal}

$\mathrm{Bu}$ çalışmada, Kurtbağrı ağacı, (Ligustrum lucidum), ağaç türüne ait odun numuneleri İzmir Büyükşehir Belediyesi Park ve bahçeleri müdürlüğü deposunda kesilmiş durumda bulunan $25 \mathrm{~cm}$ çapındaki tomruktan temin edilmiştir. Deney numuneleri hazırlanırken TS 2470 (1976) standardında belirtilen esaslar dikkate alınmıştır. Tomruğun dip kısmından ilk 
önce $20 \mathrm{~cm}$ kesilerek atılmış geri kalan kısımdan deney numuneleri alınmıştır. Tomruğun geometrik merkezi dikkate alınarak birbirine dik iki çap doğrultusunda iki kısma kesilmiş ve öz kısmı çıkarılarak geri kalan parçalar $30 \mathrm{~mm}$ kalınlığında kesilmiştir. Deney numuneleri lif doğrultusu, uzunluk eksenine paralel ve yıllık halkalar iki yüze paralel diğer iki yüze dik olacak şekilde ölçülendirilmiştir. Deney numuneleri ölçülendirilirken; budaksız, düzgün lifli, odun kusuru içermeyen ve çatlaksız, renk farkı olmayan, reaksiyon odunu bulunmamasına, mantar ve böcek zararına uğramamış olmasına, diri odun kısımlarından radyal yön dikkate alınarak kesilmesine özen gösterilmiştir. Kesilen kereste parçaları oda şartlarında (气 $18-20^{\circ} \mathrm{C}$ arası sıcaklık ve $\% 50$ bağıl nem) kurutulmaya bırakılmış ve 6 aylık bir bekleme süresinden sonra deney numuneleri hazırlanmıştır. Kurtbağrı odununa ait deney numuneleri $20 \pm 2^{\circ} \mathrm{C}$ sıcaklık ve $\%$ 65 \pm 5 bağıl nem şartlarında değişmez ağırlığa ulaşıncaya kadar iklimlendirme kabininde bekletilmiştir.

\subsection{Metot}

\subsubsection{Hava kurusu yoğunluğunun belirlenmesi}

Hava kurusu yoğunluk değeri TS 2472 (1976) standardı dikkate alınarak 20 x 20 x 30 mm boyutlarındaki numuneler üzerinde yapılmıştır. Aşağıda verilen 1 numaralı formül ile sonuçlar hesaplanmıştır.

$$
\delta_{12}:\left(\mathrm{M}_{12} / \mathrm{V}_{12}\right)\left(\mathrm{g} / \mathrm{cm}^{3}\right)
$$

$\mathrm{Bu}$ eşitlikte; $\delta_{12}$ : Hava kurusu yoğunluk $\left(\mathrm{g} / \mathrm{cm}^{3}\right), \mathrm{M}_{12}$ : Hava kurusu haldeki ağırlık $(\mathrm{g}), \mathrm{V}_{12}$ : Hava kurusu haldeki hacmi $\left(\mathrm{cm}^{3}\right)$ değerlerini ifade etmektedir.

\subsubsection{Statik sertlik direncinin belirlenmesi}

Çalışmada, statik sertlik direnci TS 2479 (1976) standardına göre 50 x 50 x $50 \mathrm{~mm}$ boyutlarında hazırlanan numuneler üzerinde yapılmıştır. Deney ALŞA marka, hidrolik sistemle çalışan deney cihazında yapılmıştır. Yük miktarı (Newton) olarak aşağıdaki formülle (2) belirlenmiştir.

$$
\mathrm{Hj}=\mathrm{K} \times \mathrm{P}_{\max }\left(\mathrm{N} / \mathrm{mm}^{2}\right)
$$

Bu eşitlikte;

$\mathrm{Hj}$ : Statik sertlik değeri $\left(\mathrm{N} / \mathrm{mm}^{2}\right)$

$\mathrm{P}_{\max }$ : Yükleme ucunun deney parçasının içerisinde belirli derinliğe girmesi sırasındaki yük $(\mathrm{N})$

$\mathrm{K}$ : Yükleme ucunun $5.64 \mathrm{~mm}$ derinliğe girmesi halinde 1'e, $2.82 \mathrm{~mm}$ derinliğe girmesi halinde ise 4/3'e eşit olan bir katsayıdır. Bu çalışmada, deney numunelerinde çatlama olmadığı için, her grup için K değeri 1 olarak alınmıştır.

\subsubsection{Eğilme direnci ve eğilmede elastikiyet modülünün belirlenmesi}

Eğilme direnci (TS 2474, 1976) ve eğilmede elastikiyet modülü (TS 2478, 1976) 20 x 20 x 360 mm ölçülerinde hazırlanmış olan deney numuneleri üzerinde yapılmıştır. Deneyler Robutest yazılım programına sahip ALŞA marka, hidrolik sistemle çalışan, malzeme test cihazında yapılmıştır. Eğilme direncinde mesnetler arası mesafe $30 \mathrm{~cm}$ olarak ayarlanmıştır.

\subsubsection{Vida tutma kapasitesinin belirlenmesi}

Vida tutma kapasitesi TS EN 13446 (2005) standardına göre 50 x 50 x 50 mm ölçülerinde deney numuneleri kullanarak belirlenmiştir. Deneyler Robutest yazılım programına sahip ALŞA marka, hidrolik sistemle çalışan, statik malzeme deney cihazında yapılmıştır. Vida tutma kapasitesinin belirlenmesinde, 4 x $50 \mathrm{~mm}$ ölçülerinde çinko vida kullanılmıştır. Vidalar takılmadan önce deney numunelerine, Bosch marka PBD40 model 
lazer işaretlemeli dikey matkap ile $2.5 \mathrm{~mm}$ çapında kılavuz delik açılmış ve vidalar $20 \mathrm{~mm}$ ağaç malzeme içerisine girecek şekilde ayarlanmıştır. Vida tutma kapasitesi denemeleri statik malzeme deney cihazının hızı $5 \mathrm{~m} / \mathrm{dk}$ olarak ayarlanmıştır. Tüm denemelerde 20 adet test örneği kullanılmıştır. 3 no'lu formül kullanılarak vida tutma kapasitesine ait sonuçlar hesaplanmıştır.

$$
f=\left[\left(F_{\max }\right) /\left(d \times l_{p}\right)\right] \mathrm{N} / \mathrm{mm}^{2}
$$

Burada; $f$ : Vidanın geri çekilmeye karşı gösterdiği direnç $\left(\mathrm{N} / \mathrm{mm}^{2}\right), l_{p}$ : Bağlayıcının girme derinliği (mm), d: İmalâtçı tarafından verilen çap $(\mathrm{mm}), F_{\max }$ : En büyük geri çıkma yükü $(\mathrm{N})$.

\section{3. İstatistiksel Analizin Belirlenmesi}

Çalışmada elde edilen veriler kullanılarak, bir istatistik programı ile varyans analizleri, aritmetik ortalama, standart sapma, en yüksek ve en düşük değerler hesaplanmış olunup, sonuçlar çizelgeler halinde sunulmuştur.

\section{Bulgular ve Tartışma}

$\mathrm{Bu}$ çalışmada deney numunelerinin ayrı ayrı hava kurusu yoğunluk $\left(\mathrm{D}_{12}\right)$ değerleri hesaplanmıştır. Hava kurusu yoğunluk değeri ortalama $791.53 \mathrm{~kg} / \mathrm{m}^{3}$ olarak belirlenmiş olup $742.55-837.19 \mathrm{~kg} / \mathrm{m}^{3}$ arasında değiştiği tespit edilmiştir. Literatürde kurtbağrı odununun fiziksel ve mekanik özellikleri ile ilgili çalışmaya rastlanmamıştır. Diğer odun türleri ile ilgili yapılan bazı araştırmalarda kayın $0.60 \mathrm{gr} / \mathrm{cm}^{3}$, ceviz $0.78 \mathrm{gr} / \mathrm{cm}^{3}$, göknar $0.49 \mathrm{gr} / \mathrm{cm}^{3}$, karaçam $0.43 \mathrm{gr} / \mathrm{cm}^{3}$, kızılçam $0.46 \mathrm{gr} / \mathrm{cm}^{3}$, kavak $0.37 \mathrm{gr} / \mathrm{cm}^{3}$, gülibrişim $0.53 \mathrm{gr} / \mathrm{cm}^{3}$ ve kayıs1 $0.788 \mathrm{~g} / \mathrm{cm}^{3}$ olarak tespit edilmiştir (Örs ve Keskin 2001, Tunçtaner ve ark., 2004, Bektaş ve ark., 2005, Çavuş 2019a, Çavuş 2020a). Odunun yoğunluğu ile fiziksel, mekanik, termik, akustik, elektriksel, morfolojik ve biyolojik özellikleri arasındaki ilişki, yapılan birçok çalışmada ortaya konulmuştur. (Malkoçoğlu 1994, Bozkurt ve Erdin 1995). Genel bir kural olarak darbe direnci, eğilme direnci, eğilmede elastikiyet modülü arasında yoğunluk artışına paralel olarak artan bir ilişki vardır (Bal ve Bektaş 2018). Kurtbağrı odununda belirlenmiş olan vida tutma direncine ait değerler Çizelge 1'de gösterilmektedir. Vida tutma direnci teğet, radyal ve enine yönler için sırasıyla $41.04 \mathrm{~N} / \mathrm{mm}^{2}, 43.93 \mathrm{~N} / \mathrm{mm}^{2}$ ve $34.77 \mathrm{~N} / \mathrm{mm}^{2}$ olarak belirlenmiştir. Vida tutma direnci yüzeyleri birbirleriyle kıyaslandığında, en yüksek değer radyal yüzeyde belirlenirken bunu teğet ve enine yönler takip etmiştir.

Çizelge 1. Vida tutma direncine (teğet, radyal ve enine yönler) ait değerler $\left(\mathrm{N} / \mathrm{mm}^{2}\right)$

\begin{tabular}{|c|c|c|c|c|c|c|c|}
\hline Test Yüzey Yönü & N & Ortalama & Standart sapma & HG & Minimum & Maksimum & Varyasyon Katsayısı \\
\hline Teğet & $\mathbf{1 6}$ & 41.04 & 2.90 & B & 37.80 & 48.50 & 7.07 \\
\hline Radyal & $\mathbf{1 6}$ & 43.93 & 3.47 & A* & 38.60 & 50.10 & 7.90 \\
\hline Enine & $\mathbf{1 6}$ & 34.77 & 4.67 & C & 28.20 & 46.30 & 13.43 \\
\hline \multicolumn{6}{|c|}{ N: Ölçüm Sayısı, HG: Homojenlik Grubu, *: En yüksek değeri ifade etmektedir. } \\
\hline
\end{tabular}

Vida tutma direnci için varyans analizi sonucu Çizelge 2'de gösterilmektedir. Çizelge 3'e göre, vida tutma direnci için test yüzey yönü anlamlı olarak belirlenmiştir.

Çizelge 2. Vida tutma direnci için varyans analizi sonucu

\begin{tabular}{|c|c|c|c|c|c|}
\hline Varyans Kaynağı & Kareler Toplamı & Serbestlik Derecesi & Ortalama Kare & F Değeri & $\boldsymbol{\alpha} \leq \mathbf{0 . 0 5}$ \\
\hline Test Yüzeyi & 701.409 & 2 & 350.704 & 24.933 & $0.000^{*}$ \\
\hline Hata & 632.964 & 45 & 14.066 & & \\
\hline Toplam & 77798.740 & 48 & & & \\
\hline \multicolumn{7}{|c|}{ *: Anlamlı } \\
\hline
\end{tabular}


Bazı ağaç türlerinde belirlenmiş olan vida tutma kapasitelerinin karşılaştırılmasına ait veriler Çizelge 3'de verilmiştir. Odunun radyal, teğet ve enine yönünün diğer mekanik özellikleri etkilediği gibi vida tutma kapasitesi üzerine de etkisi vardır. Yapılan çalışmada kurtbağrı odunun vida tutma direncinin, bu üç temel yünde farklılık gösterdiği tespit edilmiştir. Vida tutma kapasitesinin belirlenmesi için yapılan önceki çalışmalarda da benzer veriler elde edilmiştir. Yoğunluk arttıkça vida tutma kapasitesi artmaktadır (Bal ve ark., 2016). Odun hücrelerinin gövde eksenine paralel dizilişi, yıllık halkaların her bir yüzeydeki farklı konumu bu durumu etkilemektedir. Teğet yüzeyde yıllık halkalar üst üste binmiş mikro tabakalar olduğu için vidanın bu yüzeyde tutunması daha güçlü; enine yüzeyde ise vidanın yıllık halkalara paralel bir tutunması söz konusu olduğu için tutunma daha zayıftır (Efe 2020).

Çizelge 3. Bazı ağaç türlerinde belirlenmiş olan vida tutma kapasitelerinin kıyaslanması

\begin{tabular}{|c|c|c|c|c|}
\hline \multirow{2}{*}{ Ağaç Türü } & \multicolumn{3}{|c|}{ Vida Tutma Kapasitesi $\left(\mathrm{N} / \mathrm{mm}^{2}\right)$} & \multirow{2}{*}{ Kaynak } \\
\hline & Teğet & Radyal & Enine & \\
\hline Tespih (Melia azedarach L.) & 35.66 & 30.31 & 24.02 & Çavuş ve Ayata (2018) \\
\hline Japon akçaağacı (Acer Palmatum) & 35.10 & 33.10 & 28.90 & Efe $(2020)$ \\
\hline Akçaağaç (Acer trautvetteri Medw.) & 39.91 & 36.63 & 33.45 & Çavuş ve Ayata (2018) \\
\hline Manolya (Magnolia grandiflora) & 38.40 & 32.53 & 30.40 & Çavuş ve Ayata (2018) \\
\hline Kurtbağrı (Ligustrum lucidum) & 41.04 & 43.93 & 34.77 & Tespit \\
\hline Kay1s1 (Prunus armeniaca L.) & 48.89 & 47.34 & 44.38 & Çavuş (2020a) \\
\hline Turunç (Citrus aurantium L.) & 55.80 & 57.70 & 52.60 & Çavuş (2020c) \\
\hline Çitlembik (Celtis australis L.) & 58.10 & 59.60 & 55.80 & Çavuş (2020b) \\
\hline
\end{tabular}

Kurtbağrı odununda belirlenen ait janka sertlik direnci için varyans analizi sonucu Çizelge 4'te gösterilmektedir. Çizelge 4 incelendiğinde, janka sertlik direnci için test yüzey yönü anlamlı olarak bulunmuştur.

Çizelge 4. Janka sertlik direnci için varyans analizi sonucu

\begin{tabular}{|c|c|c|c|c|c|}
\hline Varyans Kaynağı & Kareler Toplamı & Serbestlik Derecesi & Ortalama Kare & F Değeri & $\boldsymbol{\alpha} \leq \mathbf{0 . 0 5}$ \\
\hline Test Yüzeyi & 4607.354 & 2 & 2303.677 & 38.618 & $0.000^{*}$ \\
\hline Hata & 3400.255 & 57 & 59.654 & & \\
\hline Toplam & 488121.540 & 60 & & & \\
\hline \multicolumn{5}{|c}{ *: Anlamlı } \\
\hline
\end{tabular}

Kurtbağrı odununda belirlenmiş olan janka sertlik direncine ait değerler Çizelge 5'te verilmiştir. Çizelge 5 incelendiğinde, janka sertlik direnci teğet, radyal ve enine yönler için sırasıyla $82.58 \mathrm{~N} / \mathrm{mm}^{2}, 83.97 \mathrm{~N} / \mathrm{mm}^{2}$ ve $101.82 \mathrm{~N} / \mathrm{mm}^{2}$ olarak belirlenmiştir. Janka sertlik direnci yüzeyleri birbirleriyle kıyaslandığında, en yüksek değer enine yüzeyde belirlenirken teğet ve radyal yüzeyler birbirine yakın değerler vermiştir. Çalışmada kullanılan bütün ağaç türlerinde belirlenmiş olan enine yüzeylere ait janka sertlik değerleri, radyal ve teğet yüzeylere ait janka sertlik değerlerinden yüksek elde edilmiştir. Sertlik üzerine yapılan bazı çalışmalarda odun sertliğinin odun türüne (Şanıvar ve Zorlu 1980) ve odun yönlerine göre büyük farklar gösterdiği bildirilmiştir (Ayata 2020).

Çizelge 5. Janka sertlik direncine ait değerler

\begin{tabular}{|c|c|c|c|c|c|c|c|}
\hline Test Yüzeyi & $\mathbf{N}$ & Ortalama & Standart Sapma & $\boldsymbol{H G}$ & Minimum & Maksimum & $\begin{array}{c}\text { Varyasyon } \\
\text { Katsayısı }\end{array}$ \\
\hline Teğet & $\mathbf{2 0}$ & 82.58 & 5.66 & $\mathrm{~B}$ & 75.20 & 99.00 & 6.85 \\
\hline Radyal & $\mathbf{2 0}$ & 83.97 & 8.23 & $\mathrm{~B}$ & 71.80 & 98.90 & 9.80 \\
\hline Enine & $\mathbf{2 0}$ & 101.82 & 8.90 & $\mathrm{~A} *$ & 84.00 & 116.90 & 8.74 \\
\hline \multicolumn{7}{|c|}{ N: Ölçüm Sayısı, $\boldsymbol{H G}$ : Homojenlik Grubu, *: En yüksek değeri ifade etmektedir. } \\
\hline
\end{tabular}


Çizelge 6'da bazı ağaç türlerinde belirlenmiş olan Janka sertlik (teğet, radyal ve enine yüzeylerde) direnci kıyaslamaları verilmiştir.

Çizelge 6. Bazı ağaç türlerinde belirlenmiş olan Janka sertlik direnci kıyaslamaları $\left(\mathrm{N} / \mathrm{mm}^{2}\right)$

\begin{tabular}{|c|c|c|c|c|}
\hline \multirow{2}{*}{ Ağaç Türü } & \multicolumn{3}{|c|}{ Janka Sertlik Değeri } & \multirow{2}{*}{ Kaynak } \\
\cline { 2 - 4 } & Teğet & Radyal & Enine & \\
\hline Yabani kiraz (Cerasus avium (L.) Monench) & 12.26 & 13.76 & 26.34 & Aytin (2013) \\
\hline Ayous (Triplochiton scleroxylon K. Schum.) & 21.01 & 17.89 & 28.69 & Ayata (2020) \\
\hline Duglas (Pseudotsuga menziesii (Mirb.) Franco) & 24.68 & 21.82 & 36.17 & Ay (2005) \\
\hline Kizılçam (Pinus brutia Ten.) & 39.90 & 39.10 & 59.90 & Efe ve Bal (2016) \\
\hline Kasnak meşesi (Quercus vulcanica (Boiss. and Heldr.) & 44.00 & 42.79 & 60.60 & Göker ve ark.,(2001) \\
\hline Karabiber (Piper nigrum L.) & 45.13 & 44.22 & 56.63 & Ayata (2019) \\
\hline Tespih (Melia azedarach L.) & 54.75 & 60.14 & 72.83 & Ayata (2019) \\
\hline Dişbudak (Fraxinus angustifolia Vahl.) & 70.88 & 66.63 & 105.86 & Şahin (2013) \\
\hline Dişbudak (Fraxinus angustifolia Vahl.) & 75.92 & 66.61 & 96.89 & Alioğulları (2010) \\
\hline Kurtbağrı (Ligustrum lucidum ) & $\mathbf{8 2 . 5 8}$ & $\mathbf{8 3 . 9 7}$ & $\mathbf{1 0 1 . 8 2}$ & Tespit \\
\hline Erik (Prunus domestica L.) & 103.24 & 103.28 & 124.31 & Ayata (2019) \\
\hline
\end{tabular}

Kurtbağr1 odununda belirlenmiş olan eğilme direncine değeri $98.66 \mathrm{~N} / \mathrm{mm}^{2}$ olarak belirlenmiş olunup $75.72-117.70 \mathrm{~N} / \mathrm{mm}^{2}$ arasında değiştiği tespit edilmiştir. Çeşitli odunların eğilme direnci ve eğilmede elastikiyet modülü üzerine yapılan bazı önceki çalışmalarda benzer değerler elde edilmiştir. Bu sonuçlara ait değerler Çizelge 7'de karşılaştırma yapılması için gösterilmiştir.

Çizelge 7. Bazı ağaç türlerinde belirlenmiş olan eğilme direnci kıyaslamaları

\begin{tabular}{|c|c|c|}
\hline Ăgaç Türü & $\mathbf{N} / \mathbf{m m}^{\mathbf{2}}$ & Kaynak \\
\hline Gülibrişim (Albizia julibrissin) & 63.70 & Çavuş (2019a) \\
\hline Kizılağaç (Alnıus glutinosa (L.) Gaertn) & 75.98 & Çalıva (2011) \\
\hline Manolya (Magnolia grandiflora L.) & 85.56 & Çavuş (2019b) \\
\hline Yabani kiraz (Cerasus avium (L.) Monench) & 95.39 & Aytin (2013) \\
\hline Kurtbağrı ağacı, (Ligustrum lucidum) & $\mathbf{9 8 . 6 6}$ & Tespit \\
\hline Dişbudak (Fraxinus angustifolia Vahl.) & 115.66 & Alioğulları (2010) \\
\hline Dişbudak (Fraxinus angustifolia Vahl.) & 126.00 & Şahin (2013) \\
\hline
\end{tabular}

Kurtbağrı odununda belirlenmiş olan elastikiyet modülüne ait sonuç Çizelge 9'da gösterilmektedir. Elastikiyet modülü $6946.26 \mathrm{~N} / \mathrm{mm}^{2}$ olarak belirlenmiş olunup 4780.69 $8524.41 \mathrm{~N} / \mathrm{mm}^{2}$ arasında değiştiği tespit edilmiştir. Bazı ağaç türlerinde belirlenmiş olan elastikiyet modülü değerleri Çizelge 8'de verilmiştir.

Çizelge 8. Bazı ağaç türlerinde belirlenmiş olan elastikiyet modülü kıyaslamaları

\begin{tabular}{|c|c|c|}
\hline Ağaç Türü & $\begin{array}{c}\text { Elastikiyet modülü } \\
\left(\mathbf{N} / \mathbf{m m}^{\mathbf{2}}\right)\end{array}$ & Kaynak \\
\hline Gülibrişim (Albizia julibrissin) & 5029.00 & Çavuş (2019a) \\
\hline Manolya (Magnolia grandiflora L.) & 6375.66 & Çavuş (2019b) \\
\hline Kokar Ardıç (Juniperus foetidissima Willd.) & 6701.50 & Çavuş (2020d) \\
\hline Kurtbağrı ağacı, (Ligustrum lucidum) & $\mathbf{6 9 4 6 . 2 6}$ & Tespit \\
\hline Kızılağaç (Alnıus glutinosa (L.) Gaertn) & 7434.05 & Çantonis ve Birbilis (2010) \\
\hline Ilgın (Tamarix aphylla) & 7533.00 & Alioğulları (2010) \\
\hline Dişbudak (Fraxinus angustifolia Vahl.) & 9876.52 & Aytin (2013) \\
\hline Yabani kiraz (Cerasus avium (L.) Monench) & 12793.80 & \\
\hline
\end{tabular}




\section{Sonuçlar ve Öneriler}

$\mathrm{Bu}$ çalışmada, kurtbağrı (Ligustrum lucidum) odun türünün; eğilmede elastikiyet modülü, eğilme direnci hava kurusu yoğunluk teğet, radyal ve enine yöndeki sertlik ve vida tutma dirençleri tespit edilmiştir. Elde edilen sonuçlara göre:

- Hava kurusu yoğunluk değeri ortalama $791.53 \mathrm{~kg} / \mathrm{m}^{3}$ olarak tespit edilmiştir.

- Eğilme direnci değeri $98.66 \mathrm{~N} / \mathrm{mm}^{2}$ ve eğilmede elastikiyet modülü değeri $6946.26 \mathrm{~N} / \mathrm{mm}^{2}$ olarak tespit edilmiştir.

- Vida tutma dirençleri teğet, radyal ve enine yüzeylerde sirasıyla 41.04, 43.93 ve 34.77 $\mathrm{N} / \mathrm{mm}^{2}$ olarak ve janka sertlik direnci teğet, radyal ve enine yüzeylerde sirasiyla 82.58 , 83.97 ve $101.82 \mathrm{~N} / \mathrm{mm}^{2}$ olarak tespit edilmiştir. Odunun üç temel yönünün, vida tutma direnci ve sertlik üzerinde önemli bir etkisinin olduğu tespit edilmiştir. Kurtbağrı odunun vida tutma direnci ve janka sertlik bu üç temel yünde farklılık gösterdiği tespit edilmiştir.

- Kurtbağrı odunu yüksek sertlik derecesi ve eğilme direnci istenilen merdiven, döşeme kaplamasında, parke yapımında, ayakkabı kalıplarında, müzik aletleri yapımında, alet yapımında, oyuncak ve ambalaj yapımında, her türlü tornacılık işlerinde ve mobilya yapımında kullanılabilir.

\section{Teşekkür}

$\mathrm{Bu}$ araştırmada; deneylerin yapılması konusunda değerli katkı ve desteklerini gördüğüm Sayın Prof. Dr. Bekir Cihad BAL'a ve deney numunelerinin temini konusunda üstün çaba ve yardımlarını gördüğüm Nesimi KILIÇ Bey’e sonsuz teşekkür ederim.

\section{Kaynaklar}

Alioğulları, S., (2010), Süleymaniye plantasyonlarında uygulanan dikim aralığının dar yapraklı dişbudak (Fraxinus angustifolia Vahl.) odununun bazı mekanik özelliklerine etkisi, Düzce Üniversitesi, Fen Bilimleri Enstitüsü, Yüksek Lisans Tezi.

Ay, N., (2005), Duglas (Pseudotsuga menziesii (Mirb.) Franco) odununun janka sertlik değeri, Kafkas Üniversitesi Artvin Orman Fakültesi Dergisi, 6(1-2), 11-16.

Ayata, Ü., (2019), İzmir yöresinde yetişen erik, karabiber ve tespih odunlarının statik sertliğinin belirlenmesi üzerine bir araştırma, Mobilya ve Ahşap Malzeme Araştırmaları Dergisi, 2(2), 94-102. DOI: 10.33725/mamad.571364.

Ayata, Ü., (2020), Ayous odununun baz1 teknolojik özelliklerinin belirlenmesi ve 1s1l işlemden sonra renk ve parlaklık özellikleri, Mobilya ve Ahşap Malzeme Araştırmaları Dergisi, 3(1), 22-33. DOI: 10.33725/mamad.724596.

Aytin, A., (2013), Yabani kiraz (Cerasus avium (L.) Monench) odununun fiziksel, mekanik ve teknolojik özellikleri üzerine yüksek sıcaklık uygulamasının etkisi, Düzce Üniversitesi, Fen Bilimleri Enstitüsü, Doktora Tezi.

Bagi, E., Baseri, B., (2021), Pyrolysis of Ligustrum vulgare waste and the effects of various operating parameters on bio-oil upgrading, Biomass Conversion and Biorefinery, DOI: 10.1007/s13399-021-01374-4.

Bailey, L.H., (1922), The Standard Cyclopedia of Horticulture, New York, NY: Macmillan, $1859 \mathrm{p}$.

Bailey, L.H., (1963), The standard cyclopedia of horticulture, The MacMillan Co.: New York. 
Bal B.C., Bektaş İ., (2018), Odunun yoğunluğu ile bazı mekanik özellikleri arasındaki ilişkinin belirlenmesi üzerine bir araştırma, Mobilya ve Ahşap Malzeme Araştırmaları Dergisi, 1(2), 51-61.

Bal, B.C., (2016), The effect of moisture content on the screw holding capacity of birch and pine plywood, International Forestry Symposium-IFS2016, 7-10 December 2016, Procedings books P: 1020-1026, Kastamonu

Bektaş, İ., Alma, H., Fidan, S., (2005), Doğu Çınarı (Platanus Orientalis)'nın lambri yapımına uygunluğunun araştırılması, Kahramanmaraş Sütçü İmam Üniversitesi, Araştırma Projeleri Yönetim Birimi Başkanlığı, Proje No: 2003/1-5: 17.

Bozkurt, Y., Erdin, N., (1995), Yoğunluk ile mekanik özellikler arasındaki ilişkiler. İstanbul Üniversitesi Orman Fakültesi Dergisi, 45(2): 11-34.

Brosse, J., (1979), Atlas of shrubs and lianes; Bordas Editions: Paris.

Cothran, J.R., (2003), Gardens and Historic Plants of the Antebellum South, The University of South Carolina Press, 217 p.

Çalıva, Z., (2011), Kızılağaç ve doğu ladini odunlarının bazı fiziksel ve mekanik özellikleri üzerine 1sıl işlemin etkisi, Karabük Üniversitesi, Fen Bilimleri Enstitüsü, Yüksek Lisans Tezi.

Çavuş, V., (2019a), İzmir'de yetişen gülibrişim (Albizia julibrissin) odununun bazı mekanik ve fiziksel özellikleri ile yüzey özelliklerinin belirlenmesi, Türkiye Ormancılık Dergisi, 20(4), 440-447. DOI: 10.18182/tjf.611994.

Çavuş, V., (2019b), Manolya (Magnolia grandiflora L.) odununun bazı fiziksel ve mekanik özellikleri, MAS 10th International European Conference on Mathematics, Engineering, Natural \& Medical Sciences, December 14-15, 2019, İzmir, Türkiye, 44-52.

Çavuş, V., (2020a), Kayısı ağacı (Prunus armeniaca L.) odununun bazı fiziksel ve mekanik özelliklerinin belirlenmesi, Bartın Orman Fakültesi Dergisi, 22(2), 457-464. DOI: 10.24011/barofd.729707.

Çavuş, V., (2020b), Çitlembik (Celtis australis L.) odununun bazı fiziksel ve mekanik özelliklerinin belirlenmesi, 1st International Hazar Scientific Research Conference, 1820 September 2020, Baku, Azerbaijan, 912-927.

Çavuş, V., (2020c), Turunç odununun bazı mekanik özelliklerinin belirlenmesi ve diğer bazı ağaç odunları ile karşılaştırılması, Mobilya ve Ahşap Malzeme Araştırmaları Dergisi, 3(2), 101-109. DOI: 10.33725/mamad.828000.

Çavuş, V., (2020d), Kokulu ardıç odununun bazı fiziksel ve mekanik özellikleri üzerine bir araştırma, Mobilya ve Ahşap Malzeme Araştırmalar Dergisi, 3(1), 1-9. DOI: 10.33725/mamad.717060.

Çavuş, V., Ayata, Ü., (2018), Manolya ağacı, akçaağaç ve tespih ağacı odunlarında vida tutma direnci üzerine bir araştırma, Mobilya ve Ahşap Malzeme Araştırmaları Dergisi, 1(2), 94-102. DOI: 10.33725/mamad.496615.

Dirr, M.A., (2009), Manual of Woody Landscape Plants: Their Identification, Ornamental Characteristics, Culture, Propagation and Uses, 6th ed. Champaign, IL: Stipes. 641 p.

Efe, F.T., (2020), Japon akçaağaç odununun bazı fiziksel ve mekanik özelliklerinin belirlenmesi üzerine bir çalışma, Mobilya ve Ahşap Malzeme Araştırmaları Dergisi, 3(2), 110-118. DOI: 10.33725/mamad.837309. 
Efe, F.T., Bal, B.C., (2016), Yüksek sıcaklıkta 1sıl işlem görmüş kızılçam (Pinus brutia Ten.) odununun sertlik değerlerinde meydana gelen değişmeler, Afyon Kocatepe Üniversitesi Fen ve Mühendislik Bilimleri Dergisi, Özel Sayı, 79-86.

Enescu, C.M., Loghin C.C., Ştefan, V., (2015), Wild privet (Ligustrum vulgare L.): A Multipurpose Species with an important role in Forest Land Reclamation Journal of Horticulture, Forestry and Biotechnology, 19(1), 70-73.

Göker, Y., As, N., Ünsal, Ö., (2001), Kasnak meşesi (Quercus vulcanica (Boiss. and Heldr.) Kotschy.) odununun bazı teknolojik özellikleri, İstanbul Üniversitesi Orman Fakültesi Dergisi, 51(1), 33-42.

Gratani, L., Foti, I., (1998), Estimating forest structure and shade tolerance of the species in a mixed deciduous broad-leaved forest in Abruzzo, Italy, Annales Botanici Fennici, 35(2): $75-83$.

Grubb, P.J., Lee, W.G., Kollmann, J., Wilson, J.B., (1996), Interaction of irradiance and soil nutrient supply on growth of seedlings of ten European tall-shrub species and Fagus sylvatica. Journal of Ecology, 84(6), 827-840. DOI: 10.2307/2960555.

Lieutaghi, P., (1975), The book of trees and shrubs; Rizzoli Editore: Milano, Italy.

Mabey, R., (1979), Plants with a Purpose, Fontana, ISBN 0-00-635555-2.

Malkoçoğlu, A., (1994), Doğu kayını (Fagus orientalis L.) odununun teknolojik özellikleri, Karadeniz Teknik Üniversitesi, Fen Bilimleri Enstitüsü, Doktora Tezi.

Mantanis, G.I., Birbilis, D., (2010), Physical and mechanical properties of athel wood (Tamarix aphylla), Süleyman Demirel Üniversitesi Orman Fakültesi Dergisi, 2: 82-87.

Mogosanu, G.D., Buteică, S.A., Purcaru, S.O., Croitoru, O., Georgescu, A.M., Serban, F., Tătăranu, L.G., Alexandru, O., Dricu, A., (2016), Rationale and in vitro efficacy of Ligustrum vulgare hydroalcoholic extract for the treatment of brain tumors, International Journal of Clinical and Experimental Pathology, 9(8), 8286-8296.

Obeso, J.R., and Grubb, P.J., (1993), Fruit maturation the shrub Ligustrum vulgare (Oleaceae): lack of defoliation effects, Oikos, 68(2), 309-316. DOI: 10.2307/3544844.

Örs, Y., Keskin, H., (2001), Ağaç Malzeme Bilgisi. KOSGEB. Kale Matbaacılık Ofset, Ankara, s. 89-92.

Pieroni, A., Pachaly, P., (2000), An ethnopharmacological study on common privet (Ligustrum vulgare) and phillyrea (Phillyrea latifolia), Fitoterapia, 71(1), S89-S94. DOI: 10.1016/S0367-326X(00)00182-9.

Polunin, O., (1969), Flowers of Europe - A Field Guide, Oxford University Press, ISBN 0192176218.

Qin, X.K., (2009), A new system of Ligustrum (Oleaceae), Acta Botanica Yunnanica, 31: $97-$ 116.

Şahin, H.İ., (2013), Isıl işlemin doğal ve plantasyon ormanlarında yetişen dişbudak (Fraxinus angustifolia Vahl.) odunlarının bazı teknolojik özelliklerine etkisi, Düzce Üniversitesi, Fen Bilimleri Enstitüsü, Doktora Tezi.

Şanıvar, N., Zorlu, İ., (1980), Ağaç işleri gereç bilgisi temel ders kitabı, Mesleki Ve Teknik Öğretim Kitapları, Milli Eğitim Basımevi, İstanbul, Etüd ve Programlama Dairesi Yayınları No: 43, 472 sayfa. 
Şofletea, N., Curtu, L., (2007), Dendrologie, Editura Universităţii Transilvania din Braşov, $540 \mathrm{p}$.

TS 2470, (1976), Odunda fiziksel ve mekaniksel deneyler için numune alma metotları ve genel özellikler, Türkiye Standartlar Enstitüsü, Ankara, 30.

TS 2472, (1976), Odunda, fiziksel ve mekaniksel deneyler için birim hacim ağırlığı tayini, Türkiye Standartlar Enstitüsü, Ankara, 31.

TS 2474, (1976), Odunun statik eğilme dayanımının tayini, Türkiye Standartlar Enstitüsü, Ankara, 32.

TS 2478, (1976), Odunun statik eğilmede elastikiyet modülünün tayini, Türk Standartları Enstitüsü, Ankara, 34.

TS EN 13446, (2005), Ahşap esaslı levhalar-Bağlayıcıların geri çıkma kapasitesinin tayini, , Türkiye Standartlar Enstitüsü, Ankara

Tunçtaner, K., As, N., Özden, Ö., (2004), Bazı kavak klonlarının büyüme performansları, odunlarının bazı teknolojik özellikleri ve kâğıt üretimine uygunlukları üzerine araştırmalar, Çevre ve Orman Bakanlığı, Yayın No: 212, ISSN:1300-395X Müdürlük Yayın No: 239, Teknik Bülten No: 196: 29, Ankara

Uphof, J.C.Th., (1959), Dictionary of Economic Plants, Weinheim.

URL, 1. file:///C:/Users/DELL/Downloads/LigustrumPollenNewInsightsIntoAllergicDisease. Erişim tarihi: 24-04-2021.

URL, 2. https://cdn.istanbul.edu.tr/statics/www.istanbul.edu.tr/wp-content/uploads/. Erişim tarihi: 24-04-2021

URL, 3. file:///C:/Users/DELL/Downloads/ANG-5\%20-\%202016.pdf. Erişim tarihi: 24-042021

URL,

https://www.izmir.bel.tr/YuklenenDosyalar/Yayinlar/0_08022018_061455_kulturpark Erişim tarihi: 24-04-2021.

URL, 5https://www.healthbenefitstimes.com/wild-privet/ Erişim tarihi: 24-04-2021.

Usher, G., (1974), A Dictionary of Plants Used by Man. Constable, ISBN 0094579202.

Weber, E., (2003), Invasive Plant Species of the World: A Reference Guide to Environmental Weeds, Cambridge, MA: CBI. 239 p. 